\title{
Optimal selling price, replenishment lot size and number of shipments for two- echelon supply chain model with deteriorating items
}

\author{
Amir Nasiri pour ${ }^{a^{*}}$ and Somayeh Najafi Ghobadi ${ }^{a^{*}}$
}

${ }^{a}$ Department of industrial engineering, Faculty of engineering, Kermanshah Branch, Islamic Azad University, Kermanshah, Iran

\begin{tabular}{l}
\hline C H R O N I C L E \\
\hline Article history: \\
Received January 16, 2017 \\
Received in revised format: \\
May 22, 2017 \\
Accepted July 23, 2017 \\
Available online \\
July 25, 2017 \\
\hline Keywords: \\
Pricing \\
Lot-sizing \\
Multiple shipments \\
Deteriorating item
\end{tabular}

A B S T R A C T

\begin{abstract}
This paper deals with a pricing and production-distribution model for a deteriorating item in a two-echelon supply chain. The profit function for the manufacturer and retailer in the integrated supply chain is derived. The manufacturer's production batch size is regulated to an integer multiple of the discrete delivery lot quantity to the retailer. The objective is to maximize the total profit per unit time by finding the optimal selling price, production lot size, total cycle time, number of deliveries, and delivery lot size, simultaneously. Based on the notion of optimal interval, we outline an effective algorithm for finding the optimal solution. Finally, the authors present a numerical example to illustrate the theoretical results of the model. Sensitivity analysis for the optimal solution with respect to major parameters is also carried out. The results show that, when the deterioration rate increases, both the optimal production lot size and cycle time decrease. It is interesting to note that an increase in the deterioration rate also tends to reduce the delivery lot size without affecting the number of deliveries per production batch. Also, the optimal interval for $\mathrm{N}$ does not change when deterioration rate changes. Reductions in the inventory cycle times for both parties demonstrate the negative effects of deterioration on the supply chain.
\end{abstract}

\section{Introduction}

Integrated or coordinated production-distribution decision has been known to be crucial in supply chain management. Conflicts among different parts of the supply chain can be diminished by effective decision and supply chain performance improves the reduction of opportunity losses caused by separate decisions. As the environment becomes more competitive, multi-stage production-distribution systems have increasingly come to the attention of the researchers. Jaber and Zolfaghari (2008) reviewed the literature on integrated supply chain and coordinated inventory management over the last two decades. Moreover, Glock (2012) provided an up-to-date review of integrated inventory models for multi-level supply chain. Many authors have developed coordination models for optimizing supply chain integrated systems. Law and Wee (2006) investigated an integrated production-inventory system of one

* Corresponding author

E-mail address: s.najafi2010@gmail.com (S. Najafi Ghobadi, A. Nasiri pour)

(C) 2018 Growing Science Ltd. All rights reserved.

doi: $10.5267 /$ j.dsl.2017.7.001 
manufacturer and one retailer with ameliorating and deteriorating items. The discounted cash flow and optimization technique were used to derive the optimal solution. Kumar et al. (2014) proposed a twoechelon inventory system to determine the optimal inventory decisions and shipment policies for a noncoordinated supply chain and a coordinated supply chain under quadratic price dependent demand. They considered a model supply chain where one product is being supplied to a single retailer by a manufacturer. Numerical illustration was carried out to compare the coordinated and non-coordinated supply chain system for the optimality of decision parameters and objective function. A supply chain including a manufacturer and several buyers with deteriorating items was investigated by Rahdar and Nookabadi (2013). In order to determine the order policies, coordination over the supply chain was achieved by scheduling the buyers' delivery days and their coordination with the manufacturer's production cycle. Pal et al. (2012) studied a multi-echelon supply chain model for multiple-markets with different selling seasons. In their model, two suppliers were involved to supply the raw materials to the manufacturer where the main supplier might face supply disruption after a random time and the secondary supplier was perfectly reliable but more expensive than the main supplier. Also the manufacturer produced a random proportion of defective items which were reworked after regular production and were sold in a lot to another market just after completion of rework. A three layer supply chain model involving a supplier, manufacturer and retailer as members of the chain was considered by Roy et.al (2012). The supply rate of raw materials, production rate of manufacturer, and the rate of demand of retailer and customers were variable. Wang et.al (2012) modeled a single-manufacturersingle-buyer supply chain problem in which the manufacturer produced a single deteriorating product and delivered it to the buyer on the basis of a consignment policy. An integrated inventory control model, jointly determining the manufacturer's production batch and the replenishment lot sizes, was proposed to minimize the manufacturer's total cost per unit time. Both scenarios of the buyer with and without warehouse capacity constraint were presented. Grubbström (2014) considered a dynamic lot sizing problem with a finite production rate. Hammami et al. (2015) incorporated carbon emissions in a multi-echelon production-inventory model with lead time constraints. They considered two types of environmental regulations: carbon emissions tax and carbon emissions cap and explained how carbon emissions are correlated to the decisions of manufacturing, ordering, and inventory.

On the other hand, the price is one of the main factors that affect the demand. Generally, reduction in selling price by the enterprises lead to increase in demand by the customers, but decrease in price is mostly restricted by total enterprises cost. Therefore, choosing an appropriate price strategy is one of the important criteria to maximize enterprises profit. There is a considerable volume of studies that deal with various aspects of joint pricing and lot sizing problem, which concerns simultaneous determination of a product's price and lot size to maximize a firm's profit for price-dependent demand over a planning horizon. In some of them, we refer the reader to recent papers by Chen et al. (2014), Lee (2014), Yang et al. (2014), Zhou and Chao (2014), and Chapter 10 in Simchi-Levi et al. (2014). A comprehensive survey of joint pricing and inventory strategies under uncertain demand was studied by Chen and Simchi-Levi (2012). Arshinder et al. (2011) and its references could present a general discussion on coordinating the supply chain.

We will provide a brief review of the literature on integrated pricing and lot size decision in a supply chain under deterministic, but price-sensitive, demand, which is most relevant to the problem considered in this paper.

The optimal selling price and order quantity for a retailer by applying a geometric programming (GP) approach was examined by Lee (1993). He considered that the demand faced by the retailer is treated as a nonlinear function of price with constant elasticity. Najafi Ghobadi et al. (2013) developed a joint pricing and inventory model for non-instantaneously deteriorating items with stochastic demand. Forghani et al. (2012) presented a single period inventory problem under a price-dependent model and suggested three functions for representing the demand rate as a function of selling price. Their research revealed a significance improvement in the system costs after the consideration of price revision. Qin et al. (2007) considered a coordination mechanism in a supply chain consisting of a supplier and a 
retailer with demand that was price- sensitive. Using an approximation method, they converted the objective functions into quadratic functions of the retail price. Yang and Wee (2006) studied a collaborative inventory system of single vendor and single buyer to maximize the total profit of the whole system. They showed that the optimal solution for the whole system is not always beneficial to both players. For ensuring mutual benefit, a negotiation factor was incorporated to share the profit between the two players according to their contributions. Jia and $\mathrm{Hu}$ (2011) investigated the joint problem of pricing and ordering for a perishable product in supply chain with one supplier and one retailer in a finite horizon. They proved that the optimal pricing strategy for the non-fresh product depends only on its inventory. Also, the optimal pricing strategy and optimal order quantity for the fresh product depend only on the wholesale price. Finally, they proposed a constant relation. Analysis of the value created from information sharing by decreasing inventory level was investigated by Ding et al. (2011), who demonstrated that investigation of the collaborative mechanism of providing incentive to retailer by upstream partner via sharing profit gained information sharing in the context of three-echelon supply chain system. Chen and Sarker (2015) studied the optimal decision for product pricing, production lot sizing in a multi-stage serial just-in-time production system with kanbancontrolled policy. Decentralized and centralized decision models of this problem were formulated as a mixed-integer nonlinear programming problem. Jonas (2013) presented a deteriorating inventory system consisting of one supplier and one buyer, which considered supplier-buyer collaboration and trade credit. The objective was to maximize the total profit of the whole system when shortage was completely backordered. Taleizadeh et al. (2014) developed an inventory model for a two-level supply chain comprised of one vendor and several non-competing retailers in which both the raw material and the finished product had different deterioration rates. They assumed that the market demand for the finished product was deterministic and price sensitive. The proposed inventory model optimized the retail price, the replenishment frequency of raw material, the replenishment cycle of the product, and the production rate jointly with main objective of maximizing the total profit of the entire chain. Nagaraju et al. (2012) developed a model for a two-level supply chain, when the demand was dependent on selling price under wholesale price index and consumer price index. Chen et al. (2010) studied coordination mechanism in a two-level supply chain by considering the lead time and price-dependent demand. They proposed risk and profit sharing agreement, which was flexible for both the parties of supply chain.

The wide variety of perishable items and the enormous number of factories and manufacturers dealing with these products as well as the application of two-echelon supply chains for their pricing, production, and distribution systems is the main motivation of this study. It has been considered a supply chain consisting of a manufacturer and a retailer which selling the perishable product produced by the manufacturer in a market, in which the demand for the product is decreasing in the price set by the retailer. A manufacturer delivers fixed quantities of a product to a retailer's warehouse at fixed time intervals. The deterioration rate for two stages is constant. Finding of the optimal policy, i.e., price, production lot size, total cycle time, number of deliveries and delivery lot size is our purpose.

The paper is organized as follows. In Section 2, at first, we describe the problems and notations which are used throughout this study. Then, Section 3 presents the mathematical formulation of the model. Theoretical results are described in Section 4. In Section 5, the solution procedure used to determine jointly the optimal pricing as well as number of deliveries and delivery lot size is presented. Finally, in Section 6, we illustrate the use of the solution procedure using a numerical example and, in Section 7 , the paper is concluded and some future research directions are provided.

\section{Assumptions and notation}

\subsection{Assumptions}

a. The production rate is constant and greater than the demand rate. 
b. The inventory item's deterioration is a constant fraction of its on-hand inventory.

c. The demand rate is a linear function of price $(a-b p)$.

d. The retailer pays transportation and order handling costs.

e. The cost of the deteriorating item is constant.

f. Shortages are not allowed.

\subsection{Notation}

$\mathrm{N}$ : The number of deliveries per production batch cycle.

Q: The production lot size per batch cycle (units).

$\mathrm{T}$ : Total cycle time (in time units).

q: Delivery lot size (units).

d: The item's deterioration rate.

$\mathrm{C}_{\mathrm{d}}$ : The cost of deterioration per unit $(\$)$.

S: Production rate for the manufacturer (units/time unit)

C: Setup cost for a production batch for the manufacturer ( $\$ /$ setup)

$\mathrm{H}_{\mathrm{m}}$ : Inventory holding cost in for the manufacturer (\$/unit/time unit)

$\mathrm{S}_{\text {sup }}$ : Area under the manufacturer's inventory level curve.

$\mathrm{p}$ : The selling price per unit

A: Ordering cost for retailer (\$/order).

$\mathrm{H}_{\mathrm{r}}$ : Inventory holding cost for retailer (\$/unit/time unit)

F: Fixed transportation cost per delivery for retailer $(\$)$

$\mathrm{V}$ : Unit variable cost for order handling and receiving for retailer (\$)

$S_{\text {buy }}$ : Area under the retailer's inventory level curve.

\section{Model development}

This paper examines an economic production quantity with multiple shipments. Consider a manufacturer that delivers fixed quantities of a product to a retailer's warehouse. Each of these deliveries arrives at the warehouse at the exact time when all items from the previous delivery have just been exhausted in fixed time intervals. The inventory time-plots for the retailer and manufacturer are shown in Fig. 1 and Fig. 2, respectively. The total cycle time T can be divided into two components; $\mathrm{T}_{1}$ : the time during which the manufacturer produces product and $\mathrm{T}_{2}$ : the time during which the manufacturer does not produce the product. Also, we let $\mathrm{T}_{3}$ be the time between two successive deliveries. 


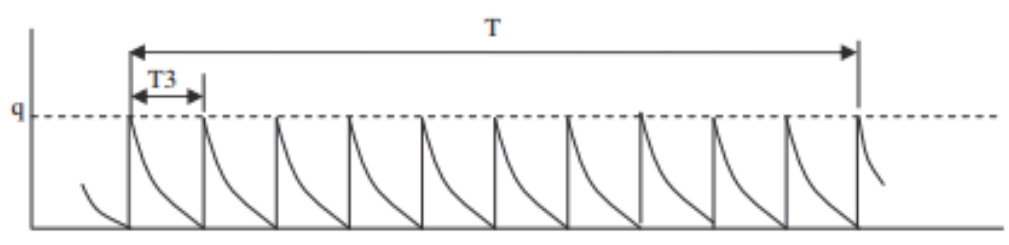

Fig. 1. Retailer's inventory level.

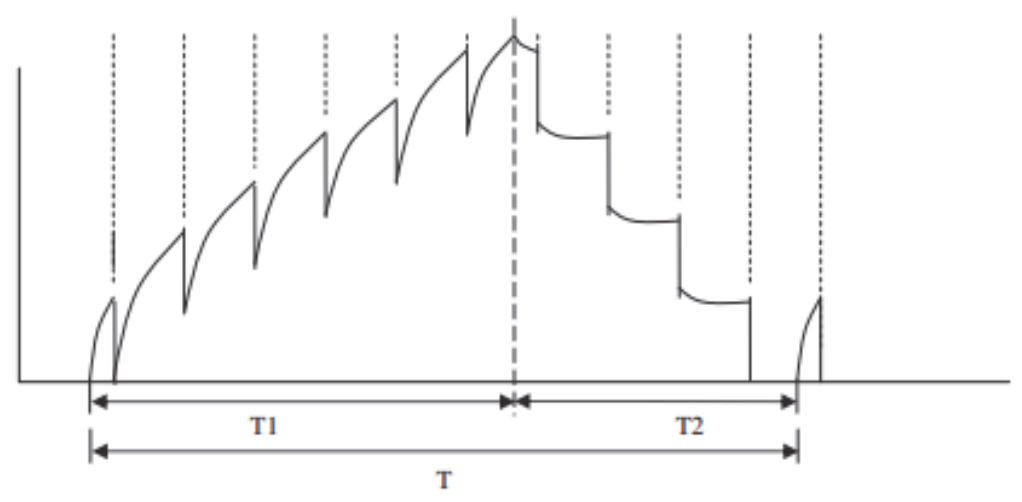

Fig. 2. Manufacturer's inventory level.

\subsection{The retailer's inventory cost model}

During each delivery cycle, the delivery lot size is

$q=\frac{d q T_{3}}{2}+(a-b p) T_{3}$.

By substituting $\mathrm{T}_{3}=\mathrm{T} / \mathrm{N}$, we obtain

$$
T=\frac{2 N q}{2(a-b p)+d q} .
$$

Also, considering total deterioration at the retailer's end, we have

$d S_{b u y}=N q-(a-b p) T$.

In other words

$$
S_{b u y}=\frac{N q-(a-b p) T}{d} .
$$

Thus, from Eq. (1) and Eq. (2), the retailer's cost function can be expressed as

$$
T P_{b u y}(q, N, p)=\frac{A}{T}+\frac{H_{r} S_{b u y}}{T}+\frac{N F+V N q}{T}+\frac{C_{d} d S_{b u y}}{T}=\left(\frac{(a-b p)}{N q}+\frac{d}{2 N}\right)(A+N F+V N q)+\frac{q}{2}\left(H_{r}+C_{d} d\right)
$$

\subsection{The manufacturer's inventory cost model}

Let $y$ be the number of deteriorated units at the manufacturer's end, therefore, 
$y=d S_{\text {sup }}$.

The total number of deteriorated units for the entire supply chain is $y+d q T / 2$ since $Q=N q+y, T_{l}=$ $(N q+y) / S$. Considering the initial inventory and the average inventory of the whole supply chain, we then have

$y+\frac{d q T}{2}=d T\left(\frac{(a-b p)}{S} q+\frac{N q+y}{2} \frac{S-(a-b p)}{S}\right)$.

Leading to

$$
S_{\text {sup }}=\frac{y}{d}=q T\left(\frac{(a-b p)}{S}-\frac{1}{2}+\frac{N}{2}-\frac{(a-b p) N}{2 S}\right)
$$

Thus, based on Eq. (1) and Eq. (4), the manufacturer's cost function can be written as

$$
T C(q, N, P)=\frac{C}{T}+\frac{H_{s} S_{\text {sup }}}{T}+\frac{C_{d} d S_{\text {sup }}}{T}=\left(\frac{(a-b p)}{N q}+\frac{d}{2 N}\right) C+\left(H_{s}+C_{d} d\right) q\left(\frac{(a-b p)}{S}-\frac{1}{2}+\frac{N}{2}-\frac{(a-b p) N}{2 S}\right)
$$

\subsection{Average profit function of integrated model}

The average total profit for the integrated model for the entire supply chain is

$$
T P(q, N, P)=p(a-b p)-\left(\frac{(a-b p)}{N q}+\frac{d}{2 N}\right)(A+C+N F+V N q)-\frac{q}{2}\left[\left(H_{r}+C_{d} d\right)+\left(H_{m}+C_{d} d\right)\left\{\frac{(2-N)(a-b p)}{S}+N-1\right\}\right]
$$

\section{Theatrical result}

The objective is to determine the optimal selling, number of deliveries and delivery lot size simultaneously such that the total profit per unit time is maximized. To achieve this goal, we should prove that for any given $p$, the optimal solution of $(\mathrm{q}, \mathrm{N})$ not only exists but also is unique. Next for any given value of $(q, N)$ there exists a unique $p$ that maximizes the total profit per unit time.

From calculus, it is well known that TP is concave if and only if the following equations are satisfied

$$
\frac{\partial^{2} T P(\mathrm{q}, \mathrm{N}, p)}{\partial q^{2}}<0 \quad \frac{\partial^{2} T P(\mathrm{q}, \mathrm{N}, p)}{\partial N^{2}}<0 \quad[q, N]\left[\begin{array}{cc}
\frac{\partial^{2} T P(\mathrm{q}, \mathrm{N}, p)}{\partial q^{2}} & \frac{\partial^{2} T P(\mathrm{q}, \mathrm{N}, p)}{\partial q \partial N} \\
\frac{\partial^{2} T P(\mathrm{q}, \mathrm{N}, p)}{\partial q \partial N} & \frac{\partial^{2} T P(\mathrm{q}, \mathrm{N}, p)}{\partial N^{2}}
\end{array}\right]\left[\begin{array}{c}
q \\
N
\end{array}\right]<0
$$

For any given $\mathrm{p}$, taking the second derivatives of $\mathrm{TP}(\mathrm{q}, \mathrm{N}, \mathrm{p}$ ) with respect to $\mathrm{q}$ and $\mathrm{N}$ is as bellow;

$$
\begin{aligned}
& \frac{\partial^{2} T P(N, q, p)}{\partial q^{2}}=\frac{-2 q(a-b p)(A+C+N F+V N q)+2 N V(a-b p)}{N q^{2}}<0 \\
& \frac{\partial^{2} T P(N, q, p)}{\partial N^{2}}=\frac{-(2(a-b p)+d q)(A+C+N F+V N q)+N q(F+V q)}{N^{3} q^{3}}<0
\end{aligned}
$$

Also

$$
\frac{\partial^{2} T P(N, q, p)}{\partial q \partial N}=-\frac{a-b p}{N^{2} q^{2}}(A+C)-\frac{1}{2}\left(H_{m}+C_{d} d\right)\left(\frac{S-(a-b p)}{S}\right)<0
$$


Thus

$$
q^{2} \frac{\partial^{2} T P(N, q, p)}{\partial q^{2}}+N^{2} \frac{\partial^{2} T P(N, q, p)}{\partial N^{2}}+2 q N \frac{\partial^{2} T P(N, q, p)}{\partial q \partial N}<0
$$

Furthermore, TP (q, N, p) is strictly concave.

The problem remaining is to find the Optimal value of $p$ which maximizes TP (q, N, p). Taking the first and second-order derivatives of TP $(\mathrm{N}, \mathrm{q}, \mathrm{p})$ with respect to $\mathrm{p}$ gives

$$
\frac{d T P(\mathrm{q}, \mathrm{N}, p)}{d p}=-2 p-a+b / N q(A+C+N F+V N q)+N b / S\left(H_{m}+C_{d} d\right), \frac{d^{2} T P(\mathrm{q}, \mathrm{N}, p)}{d p^{2}}=-2<0
$$

Therefore $\mathrm{d}^{2} \mathrm{TP}(\mathrm{q}, \mathrm{N}, \mathrm{p}) / \mathrm{dp}^{2}<0$. Consequently, TP $(\mathrm{q}, \mathrm{N}, \mathrm{p})$ is a concave function of $\mathrm{p}$ for a given $(\mathrm{q}$, $\mathrm{N})$, and hence there exists a unique value of $\mathrm{p}$ which maximizes TP (q, N, p)

Now, setting the first order derivative of the objective function with respect to $\mathrm{q}, \mathrm{N}$ and $\mathrm{p}$ equal to zero gives:

$$
\begin{aligned}
& q=\sqrt{\frac{2(a-b p)(A+C+N F)}{\left[\left(H_{r}+C_{d} d\right)+\left(H_{m}+C_{d} d\right)\left\{\frac{(2-N)(a-b p)}{S}+N-1\right\}+d V\right] N}} \\
& N=\sqrt{\frac{(2(a-b p)+d q)(A-p(a-b p)+C) S}{\left(H_{m}+C_{d} d\right) q^{2}(S-(a-b p))}} \\
& p=\frac{a+b / N q(A+C+N F+V N q)+N b / S\left(H_{m}+C_{d} d\right)}{2}
\end{aligned}
$$

In fact, the optimization problem is non-linear and it has three variables. From Eqs.8, 9 and 10, it is easy to see that all of variables are related. To obtain the values for decision variables, we find the upper limit for $\mathrm{N}$ and then suggest search-based solution procedure

\subsection{Optimal interval for $N$}

Since $\mathrm{N} \geq 1$, according to Eq. (8), q reaches its upper bound when $\mathrm{N}=1$, i.e.

$$
q \leq \sqrt{\frac{2(a-b p) S(A+C+F)}{S\left(H_{r}+C_{d} d\right)+\left(H_{m}+C_{d} d\right)(a-b p)+d V S}}
$$

When $\mathrm{N}$ increases, the corresponding q decreases. Hence, from Eq. (8), we obtain

$$
q \geq \sqrt{\frac{2(a-b p) S(A+C+N F)}{\left[\left(H_{r}+C_{d} d\right)+d V\right][2 D(p)+N(S-(a-b p))] N}}
$$

Furthermore, since $\mathrm{N} \geq 1$, Eq. (9) leads to

$$
1 \leq N \leq N_{u}=\frac{\left(H_{r}+C_{d} d\right)+d V}{\left(H_{m}+C_{d} d\right)} \frac{A+C}{F}+\sqrt{\frac{2(a-b p)\left[\left(H_{r}+C_{d} d\right)+d V\right]+d(A+C) S}{\left(H_{m}+C_{d} d\right)(S-(a-b p))}},
$$

where $\mathrm{N}_{\mathrm{u}}$ represents the upper bound on $\mathrm{N}$ 


\section{Solution procedure}

For the integrated model, we suggest the following search-based solution procedure:

Step 1: Start with the initial value of $\mathrm{p}=\mathrm{C}_{\mathrm{d}}$.

Step 2: calculate the optimal interval for $\mathrm{N}$, using inequality (12)

step 3: for all integers in this interval $\left(1, \mathrm{~N}_{\mathrm{U}}\right)$, use Eq. (7) to calculate the corresponding q values; then use Eq. (6) to calculate the resulting TP values choose the optimal $\mathrm{N}$ and q pair that results in the maximum TP in step 3 and put it in vector $\mathrm{X}$

Step 4: Replace $\mathrm{p}=\mathrm{p}+0.05 \leq \frac{a}{b}$ and go to step 2

Step 5: choose the maximum value of vector $\mathrm{X}$ and $\mathrm{N}, \mathrm{q}$ and $\mathrm{p}$ of it

\section{Numerical example}

In this section, a numerical example is presented to illustrate the model and its solution through the proposed algorithm. Example used in this study is an extended version of the illustration provided by Kim and $\mathrm{Ha}$ (2003). The data used in this example are as follows:

1. for the entire supply chain: $\mathrm{C}_{\mathrm{d}}=50$ per unit; $\mathrm{d}=0.05$

2. for the manufacturer: $S=19200$ units per year; $C=600$ per batch; $H_{m}=\$ 6 /$ unit/year.

3. For the retailer: $D(p)=4000-4 P$ units per year; $A=\$ 25$ per order; $H_{r}=\$ 7 /$ unit/year; $F=\$ 50$ per delivery; $\mathrm{v}=\$ 1 /$ unit

Under the given values of the parameters and according to the algorithm in the previous section, the computational results are as follows, the optimal selling price $p^{*}=\$ 501.15$, the number of deliveries $\mathrm{N}^{*}=2$, and the Delivery lot size $q^{*}=283.1036$. Hence the optimal production lot size $\mathrm{Q}^{*}=568$ units, the Total cycle times $(\mathrm{T}$ in days $)=103$ and optimal total average profit $\mathrm{TP}\left(\mathrm{q}^{*}, \mathrm{~N}^{*}, \mathrm{p}^{*}\right)=\$ 992830$

The numerical results with distinct starting values of $\mathrm{p}(490,495,499,501.1,505,507$, and 510) were run. The numerical results reveal that TP is strictly concave in p, as shown in Fig. 3 As a result, we are sure that the local maximum obtained here from proposed algorithm is indeed the global maximum solution.

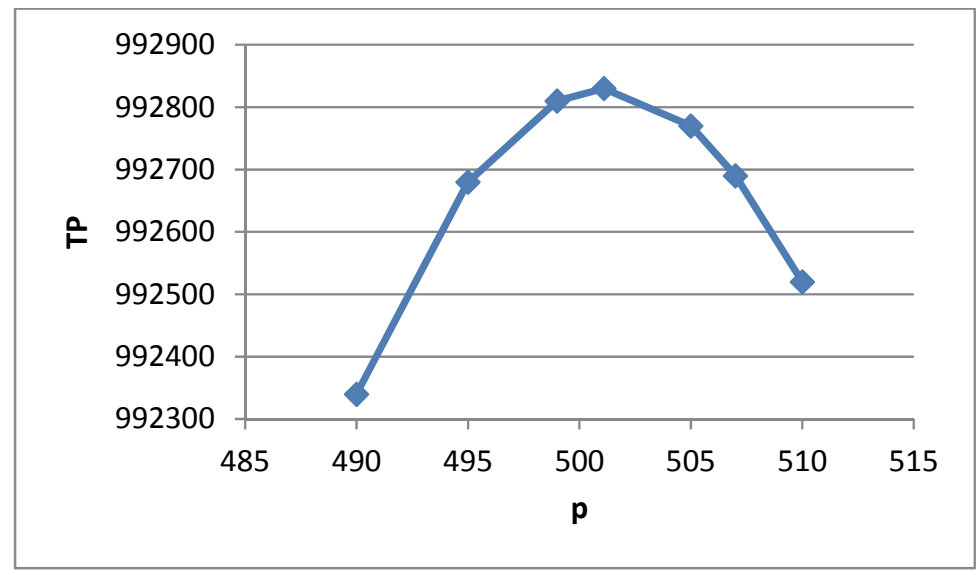

Fig. 3. Annual total system profit, TP vs. $p$ 
The solution procedure outlined above is used to find the solutions for varying values of the deterioration rate, $\mathrm{d}$, ranging from 0 to 0.2 . The results are summarized in Table 1 .

\section{Table 1}

Summary of results for different values of d

\begin{tabular}{|c|c|c|c|c|c|c|c|c|c|}
\hline $\mathrm{d}$ & 0 & 0.025 & 0.05 & 0.075 & 0.1 & 0.125 & 0.15 & 0.175 & 0.2 \\
\hline $\mathrm{P}$ & 501.05 & 501.10 & 501.15 & 501.20 & 501.25 & 501.25 & 501.30 & 501.35 & 501.40 \\
\hline Production lot size(Q) & 667 & 611 & 568 & 533 & 503 & 479 & 457 & 438 & 422 \\
\hline $\begin{array}{l}\text { Total cycle time } \\
\text { ( } \mathrm{T} \text { in days })\end{array}$ & 122 & 111 & 103 & 96 & 90 & 86 & 82 & 78 & 75 \\
\hline Number of deliveries $(\mathrm{N})$ & 2 & 2 & 2 & 2 & 2 & 2 & 2 & 2 & 2 \\
\hline Delivery lot size(q) & 333.6229 & 305.2741 & 283.1036 & 265.1440 & 250.2272 & 237.5793 & 226.6624 & 217.1224 & 208.6921 \\
\hline Total average profit(TP in $\$$ ) & 993660 & 993230 & 992830 & 992460 & 992110 & 991780 & 991460 & 991150 & 990860 \\
\hline
\end{tabular}

The results show that when the deterioration rate increases, both the optimal production lot size and the cycle time decrease (see Table 1 and Fig. 4). This is not unexpected, because when the deterioration rate increases, the corresponding cycle time and the production lot size are reduced for the benefit of the entire supply chain. It is interesting to note that an increase in the deterioration rate also tends to reduce the delivery lot size without affecting the number of deliveries per production batch. In fact, as seen in Table 1, the optimal interval for $\mathrm{N}$ does not change with varying deterioration rates. The reductions in the inventory cycle times for both the parties show the negative effects of deterioration on the supply chain. Not surprisingly, our results also indicate that, the average annual profit for the supply chain decrease when the deterioration rate goes up (see Table 1 and Fig. 5). This occurs due to the impact of deterioration on the inventory cycles because more frequent setups and deliveries are necessary.

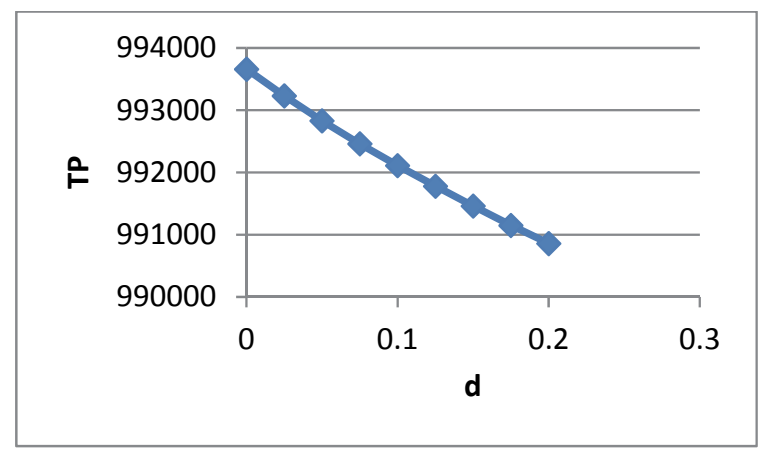

Fig. 4. Annual total system profit, TP vs. d

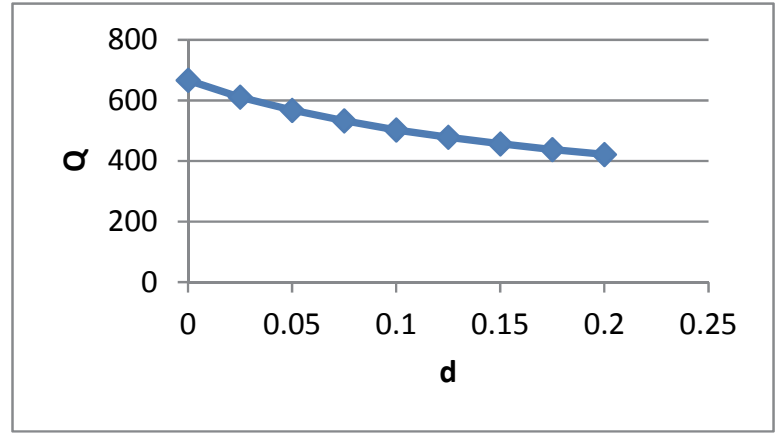

Fig. 5. Production lot size, Q vs. d

This study now investigates the effects of changes in the values of the cost parameters $\mathrm{H}_{\mathrm{m}}, \mathrm{H}_{\mathrm{r}}, \mathrm{C}, \mathrm{F}$, and $\mathrm{v}$ on $\mathrm{p}^{*}, \mathrm{q}^{*}, \mathrm{~T}^{*}, \mathrm{Q}^{*}, \mathrm{~N}^{*}$ and $\mathrm{TP} *\left(\mathrm{q}^{*}, \mathrm{~N}^{*}, \mathrm{p}^{*}\right)$ according to above Example. The sensitivity analysis is performed by changing each value of the one parameter at a time and keeping the remaining parameter values unchanged. The computational results are shown in Table 2.On the basis of the results of Table 2, the following observations can be made.

- The optimal selling price $p^{*}$ is not sensitive to changes in parameters $A$ and $\mathrm{F}$, whereas $\mathrm{p}^{*}$ is positively sensitive to changes in parameter $\mathrm{H}_{\mathrm{m}}, \mathrm{H}_{\mathrm{r}}, \mathrm{C}$ and $\mathrm{v}$.

- When values of parameters $\mathrm{H}_{\mathrm{m}}$ and $\mathrm{H}_{\mathrm{r}}$ increase, the optimal value of production lot size $\mathrm{Q}^{*}$ decrease. While it will increase as the value of parameters $\mathrm{A}, \mathrm{C}$ and $\mathrm{F}$ increase. From an economic viewpoint, this means that manufacturer will produce fewer when the holding cost increase.

- When the value of parameters $\mathrm{H}_{\mathrm{m}}$ and $\mathrm{H}_{\mathrm{r}}$ increase, the optimal length of the total cycle $\mathrm{T}^{*}$ will decrease, while it will increase as the values of parameters $\mathrm{A}, \mathrm{C}$ and $\mathrm{F}$ increase. This implies that the higher the order cost, set up cost and fixed transportation cost the longer the length of the total cycle, while the lower the holding cost of manufacturer and retailer, the longer the length of the total cycle. 
- When the value of parameter $\mathrm{H}_{\mathrm{m}}$ and $\mathrm{H}_{\mathrm{r}}$ increase, the optimal delivery lot size $\mathrm{q}^{*}$ will decrease and it will increase with an increase in the values of parameters $\mathrm{A}, \mathrm{C}$ and $\mathrm{F}$. The corresponding managerial insight is that as the order cost, fixed transportation cost and set up cost increase, the optimal delivery lot size increases.

- When the values of parameters $\mathrm{H}_{\mathrm{m}}, \mathrm{H}_{\mathrm{r}}, \mathrm{A}, \mathrm{C}, \mathrm{F}$ and $\mathrm{v}$ increase, the optimal total profit per unit time $\mathrm{TP}^{*}$ will decrease. This implies that increases in costs have a negative effect upon the total profit per unit time.

Table 2

Sensitivity analysis with respect to the model parameters

\begin{tabular}{|c|c|c|c|c|c|c|c|}
\hline & \multirow{2}{*}{ Parameter values } & \multicolumn{5}{|c|}{ Optimal Solutions } & \multirow[b]{2}{*}{ TP* } \\
\hline & & $\mathrm{P}^{*}$ & $\mathrm{Q}^{*}$ & $\mathrm{~T}^{*}$ & $\mathrm{~N}^{*}$ & $q^{*}$ & \\
\hline \multirow{3}{*}{$\mathrm{H}_{\mathrm{m}}$} & 5 & 501.1 & 585 & 106 & 2 & 291.3021 & 992970 \\
\hline & 6 & 501.15 & 568 & 103 & 2 & 283.1036 & 992830 \\
\hline & 7 & 501.15 & 553 & 100 & 2 & 275.5729 & 992690 \\
\hline \multirow{3}{*}{$\mathrm{Hr}$} & 6 & 501.1 & 584 & 106 & 2 & 291.3021 & 992970 \\
\hline & 7 & 501.15 & 568 & 103 & 2 & 283.1036 & 992830 \\
\hline & 8 & 501.15 & 553 & 100 & 2 & 275.5729 & 992690 \\
\hline \multirow{3}{*}{ A } & 20 & 501.15 & 566 & 103 & 2 & 282.1257 & 992850 \\
\hline & 25 & 501.15 & 568 & 103 & 2 & 283.1036 & 992830 \\
\hline & 30 & 501.15 & 570 & 105 & 2 & 284.0781 & 992810 \\
\hline \multirow{3}{*}{$\mathrm{C}$} & 500 & 501.1 & 527 & 96 & 2 & 262.8683 & 993200 \\
\hline & 600 & 501.15 & 568 & 103 & 2 & 283.1036 & 992830 \\
\hline & 700 & 501.2 & 606 & 110 & 2 & 301.9824 & 992480 \\
\hline \multirow{3}{*}{$\mathrm{F}$} & 40 & 501.15 & 560 & 102 & 2 & 279.1714 & 992900 \\
\hline & 50 & 501.15 & 568 & 103 & 2 & 283.1036 & 992830 \\
\hline & 60 & 501.15 & 576 & 105 & 2 & 286.9819 & 992760 \\
\hline \multirow{3}{*}{$\mathrm{v}$} & 0.75 & 501 & 568 & 103 & 2 & 283.2442 & 993340 \\
\hline & 1 & 501.15 & 568 & 103 & 2 & 283.1036 & 992830 \\
\hline & 1.25 & 501.25 & 568 & 103 & 2 & 282.9773 & 992330 \\
\hline
\end{tabular}

\section{Conclusion}

In this study, we developed an integrated single-manufacturer, single-retailer pricing and inventory model for a deteriorating item. Profit functions for the manufacturer and retailer in the integrated supply chain were derived. This paper also discussed the optimal interval for the number of deliveries per production batch cycle, which was assumed to be an integer. Based on the notion of this optimal interval, we outlined an effective procedure to determine the optimum delivery lot size to the retailer, number of deliveries, and optimal price. The results showed that, when the deterioration rate increased, both the optimal production lot size and cycle time decreased, which was not unexpected, because when the deterioration rate increased, the corresponding cycle time and the production lot size were reduced for the benefit of the entire supply chain. It is interesting to note that an increase in the deterioration rate also tended to reduce the delivery lot size without affecting the number of deliveries per production batch. Also, the optimal interval for $\mathrm{N}$ did not change with varying deterioration rates. Reductions in the inventory cycle times for both parties demonstrated the negative effects of deterioration on the supply chain. Not surprisingly, our results also indicated that the average annual profit for the supply chain decreased when the deterioration rate went up, which occurred due to the impact of deterioration on the inventory cycles and because more frequent setups and deliveries were necessary. Also, from the sensitivity analysis, it is concluded that all the model parameters have the significant influence over the optimality of selling price, production lot size, total cycle time, delivery lot size and total profit per unit time. Finally, it would be interesting for future works to study the effects of item decay allowing backorders in an integrated supply chain context. Also, uncertain demand should be considered in future works. 


\section{Acknowledgments}

We would like to thank the supports from Islamic Azad University, Kermanshah Branch

\section{References}

Arshinder, K., Kanda, A., \& Deshmukh, S. G. (2011). A review on supply chain coordination: coordination mechanisms, managing uncertainty and research directions. In Supply Chain Coordination under Uncertainty (pp. 39-82). Springer Berlin Heidelberg.

Chen, H., Chen, Y. F., Chiu, C. H., Choi, T. M., \& Sethi, S. (2010) Coordination mechanism for the supply chain with lead-time consideration and price-dependent demand. European Journal of Operational Research, 203(1), 70-80.

Chen, X., \& Simchi-Levi, D. (2012). Pricing and inventory management. The Oxford handbook of pricing management, 784-822.

Chen, X., Pang, Z., \& Pan, L. (2014). Coordinating inventory control and pricing strategies for perishable products. Operations Research, 62(2), 284-300.

Chen, Z., \& Sarker, B. R. (2015). Optimisation of multi-stage JIT production-pricing decision: centralised and decentralised models and algorithms. International Journal of Production Research, 53(20), 6210-6230.

Ding, H., Guo, B., \& Liu, Z. (2011). Information sharing and profit allotment based on supply chain cooperation. International Journal of Production Economics, 133(1), 70-79.

Forghani, K., Mirzazadeh, A., \& Rafiee, MA. (2012). price-dependent demand model in the single period inventory system with price adjustment. Journal of Industrial Engineering, 2013.

Glock, C. H. (2012). The joint economic lot size problem: A review. International Journal of Production Economics, 135(2), 671-686.

Grubbström, R. W. (2014). Dynamic lotsizing with a finite production rate. International Journal of Production Economics, 149, 68-79.

Hammami, R., Nouira, I., \& Frein, Y. (2015). Carbon emissions in a multi-echelon productioninventory model with lead time constraints. International Journal of Production Economics, 164, 292-307.

Jaber, M. Y., \& Zolfaghari, S. (2008). Quantitative models for centralized supply chain coordination. INTECH Open Access Publisher.

Jia, J., \& Hu, Q. (2011). Dynamic ordering and pricing for a perishable goods supply chain. Computers \& Industrial Engineering, 60(2), 302-309.

Jonas, C. P. (2013). A collaborative strategy for deteriorating inventory system with imperfect items and supplier credits. International Journal of Production Economics, 143(2), 403-409.

Kim, S. L., \& Ha, D. (2003). A JIT lot-splitting model for supply chain management: Enhancing buyersupplier linkage. International Journal of Production Economics, 86(1), 1-10.

Kumar, B. K., Nagaraju, D., \& Narayanan, S. (2014). Optimality of Inventory Decisions and Shipment Policies in a Two-Echelon Inventory System under Quadratic Price Dependent Demand. Procedia Engineering, 97, 2279-2288.

Law, S. T., \& Wee, H. M. (2006). An integrated production-inventory model for ameliorating and deteriorating items taking account of time discounting. Mathematical and Computer Modelling; 43(5), 673-685.

Lee, J. (2014). Dynamic pricing inventory control under fixed cost and lost sales. Applied Mathematical Modelling, 38(2), 712-721.

Lee, W. J. (1993). Determining Order Quantity and Selling Price by Geometric Programming: Optimal Solution, Bounds, and Sensitivity. Decision Sciences, 24(1), 76-87.

Nagaraju, D., Ramakrishnarao, A., \& Narayanan, S (2012). Two-echelon supply chain with selling price dependent demand under wholesale price index and consumer price index. International Journal of Logistics Systems and Management, 13(4), 417-439. 
Najafi Ghobadi, S., Nakhai Kamalabadi, I., \& Aghdasi, M. (2013). Joint Pricing and Inventory Control for Non-instantaneous Deteriorating Items with Stochastic Demand. International Journal of Supply Chain Management, 1(3).

Pal, B., Sana, S. S., \& Chaudhuri, K. (2012). A multi-echelon supply chain model for rework able items in multiple-markets with supply disruption. Economic Modelling, 29(5), 1891-1898.

Qin, Y., Tang, H., \& Guo, C. (2007). Channel coordination and volume discounts with price-sensitive demand. International Journal of Production Economics, 105(1), 43-53.

Rahdar, M., \& Nookabadi, A. S. (2014). Coordination mechanism for a deteriorating item in a twolevel supply chain system. Applied Mathematical Modelling, 38(11), 2884-2900.

Roy, A., Sana, S. S., \& Chaudhuri, K. (2012). Optimal replenishment order for uncertain demand in three layer supply chain. Economic Modelling, 29 (6), 2274-2282.

Simchi-Levi, D., Chen, X., \& Bramel, J. (2014) Integration of inventory and pricing. In The Logic of Logistics. Springer New York, 177-209.

Taleizadeh, A. A., Noori-daryan, M., \& Cárdenas-Barrón, L. E. (2015). Joint optimization of price, replenishment frequency, replenishment cycle and production rate in vendor managed inventory system with deteriorating items. International Journal of Production Economics, 159, 285-295.

Wang, S. P., Lee, W., \& Chang, C. Y. (2012). Modeling the consignment inventory for a deteriorating item while the buyer has warehouse capacity constraint. International Journal of Production Economics, 138(2), 284-292.

Yang, P. C., \& Wee, H. MA (2006). collaborative inventory system with permissible delay in payment for deteriorating items. Mathematical and computer modelling, 43(3), 209-221.

Yang, Y., Chen, Y., \& Zhou, Y. (2014). Coordinating inventory control and pricing strategies under batch ordering. Operations Research, 62(1), 25-37.

Zhou, S. X., \& Chao, X. (2014), Dynamic pricing and inventory management with regular and expedited supplies. Production and Operations Management, 23(1), 65-80.

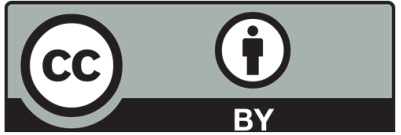

(C) 2018 by the authors; licensee Growing Science, Canada. This is an open access article distributed under the terms and conditions of the Creative Commons Attribution (CC-BY) license (http://creativecommons.org/licenses/by/4.0/). 